\title{
Lunettes connectées : médecins régulateurs, ouvrez les yeux !
}

\section{Connected Glasses: Medical Dispatchers, Open your Eyes!}

\section{T. Schmutz $\cdot$ F. Braun}

Reçu le 7 juin 2016; accepté le 20 juillet 2016

(C) SFMU et Lavoisier SAS 2016

Les lunettes connectées permettent au médecin régulateur du Samu-centre 15 de voir, en direct, l'intervention. Simple monture dotée d'une caméra, les Google ${ }^{\circledR}$ glass (Foxconn, Mountain View) transmettent les images sans que l'opérateur ne soit gêné dans ses mouvements, oubliant même qu'il les porte. Le médecin régulateur visualise, sur un écran déporté, tout ce que l'appelant voit en direct, moyen simple d'optimiser la régulation médicale, d'autant que le contact verbal reste continu entre médecin régulateur et intervenant. Le Samu-centre 15 peut même interagir avec le médecin sur le terrain par retour vidéo ou en adressant des informations sur le système d'affichage des lunettes. À l'heure où tous soulignent l'importance d'un bilan médical ou secouriste précoce, l'utilisation des lunettes connectées a permis ici d'activer au plus tôt la filière de prise en charge du traumatisé grave (Fig. 1). L'idée du médecin régulateur « gardien du temps » prend alors tout son sens.

En dehors de ce cadre, les champs d'exploitation des lunettes connectées par les Samu-centre 15 semblent multiples $[1,2]$ :

- télé-expertise médicale lors des prises en charges préhospitalières des équipes secouristes, des équipes Smur (aide à la décision et aide à la réalisation de gestes complexes comme des manœuvres obstétricales), soutien pour l'analyse de situations difficiles (accidentologie à victimes multiples, risques NRBC-E, brûlés graves, attentats...) ;

- téléconsultation lors d'appels venant de personnels paramédicaux ou médicosociaux, principalement des EHPAD ;

- téléformation sur mannequin à haute fidélité dans le cadre des CESU et retour d'expérience sur des analyses vidéo des interventions préhospitalières dans une démarche qualité.

La régulation médicale au sein de plateformes dédiées «Samu-Santé » doit rapidement s'approprier les nouvelles technologies de communication afin d'enrichir le flux

T. Schmutz $(\bowtie) \cdot$ F. Braun

Structures de médecine d'urgence, hôpital de Mercy,

CHR Metz-Thionville, 1 allée du château,

F-57085 Ars-Laquenexy, France

e-mail : t.schmutz@chr-metz-thionville.fr

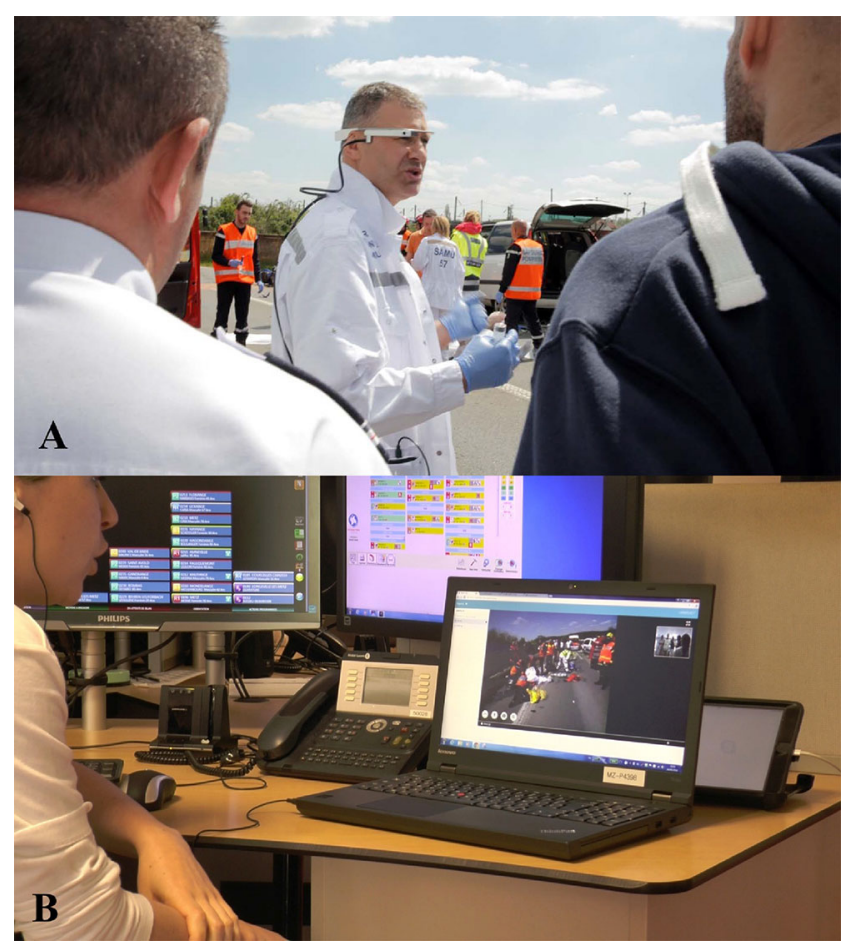

Fig. 1 Le médecin SMUR porte des lunettes connectées, simple monture dotée d'une caméra miniature (A). Au Samu-centre 15, le médecin régulateur visualise en direct l'intervention SMUR (B)

d'informations dans un souci constant d'amélioration de la qualité et de la sécurité des soins, et dans le strict respect des droits des malades.

Liens d'intérêts : Les auteurs déclarent ne pas avoir de lien d'intérêt.

\section{Références}

1. Chai PR, Babu KM, Boyer EW (2015) The feasibility and acceptability of Google Glass for teletoxicology consults. J Med Toxicol 11:283-7

2. Chang JY, Tsui LY, Yeung KS, et al (2016) Surgical vision: Google Glass and surgery. Surg Innov 23:422-6 